\title{
Yeast Gcn5 functions in two multisubunit complexes to acetylate nucleosomal histones: characterization of an Ada complex and the SAGA (Spt/Ada) complex
}

\author{
Patrick A. Grant, ${ }^{1}$ Laura Duggan, ${ }^{2}$ Jacques Côté, ${ }^{1}$ Shannon M. Roberts, ${ }^{3}$ James E. Brownell, ${ }^{4}$ \\ Reyes Candau, ${ }^{2}$ Reiko Ohba, ${ }^{4}$ Tom Owen-Hughes, ${ }^{1}$ C. David Allis, ${ }^{4}$ Fred Winston, ${ }^{3}$ \\ Shelley L. Berger, ${ }^{2,5}$ and Jerry L. Workman ${ }^{1,5}$ \\ ${ }^{1}$ Department of Biochemistry and Molecular Biology and The Center for Gene Regulation, The Pennsylvania State \\ University, University Park, Pennsylvania 16802-4500 USA; ${ }^{2}$ The Wistar Institute, Philadelphia, Pennsylvania 19104 USA; \\ ${ }^{3}$ Department of Genetics, Harvard Medical School, Boston, Massachusetts 02115 USA; ${ }^{4}$ Department of Biology, University \\ of Rochester, Rochester, New York 14627 USA
}

The transcriptional adaptor protein Gen5 has been identified as a nuclear histone acetyltransferase (HAT). Although recombinant yeast Gcn5 efficiently acetylates free histones, it fails to acetylate histones contained in nucleosomes, indicating that additional components are required for acetylation of chromosomal histones. We report here that Gen5 functions as a catalytic subunit in two high-molecular-mass native HAT complexes, with apparent molecular masses of 0.8 and 1.8 megadalton (MD), respectively, which acetylate nucleosomal histones. Both the 0.8- and 1.8-MD Gcn5-containing complexes cofractionate with Ada2 and are lost in $\operatorname{gcn} 5 \Delta, a d a 2 \Delta$, or ada3s yeast strains, illustrating that these HAT complexes are bona fide native Ada-transcriptional adaptor complexes. Importantly, the 1.8-MD adaptor/HAT complex also contains Spt gene products that are linked to TATA-binding protein (TBP) function. This complex is lost in spt20/ada5s and

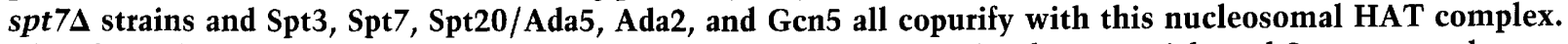
Therefore, the 1.8-MD adaptor/HAT complex illustrates an interaction between Ada and Spt gene products and confirms the existence of a complex containing the TBP group of Spt proteins as demonstrated by genetic and biochemical studies. We have named this novel transcription regulatory complex SAGA (Spt-Ada-Gen5-Acetyltransferase). The function of Gen5 as a histone acetyltransferase within the Ada and $\widehat{S A G} \bar{A}$ adaptor complexes indicates the importance of histone acetylation during steps in transcription activation mediated by interactions with transcription activators and general transcription factors (i.e., TBP).

[Key Words: Acetyltransferase; nucleosome; transcription; Spt; Ada; Gcn5]

Received March 28, 1997; revised version accepted May 15, 1997.

Chromatin structure has an intricate role in the regulation of eukaryotic gene transcription. Nucleosomes suppress basal transcription initiation in vivo and in vitro increasing the dependence of transcription on the function of sequence-specific activator proteins (for review, see Grunstein 1990; Owen-Hughes and Workman 1994). Chromatin structures are remodeled before or during transcription activation generating DNase I hypersensitive regions (DHSs) at transcription control elements (Hager et al. 1995; Steger and Workman 1996; Svaren and Horz 1996). Multiprotein complexes have been impli-

${ }^{5}$ Corresponding authors.

E-MAIL jlw10@psu.edu; FAX (814) 863-0099; berger@wista.wistar. upenn.edu; FAX (215) 898-0663. cated in this process. The yeast and human Swi/Snf complexes (Côté et al. 1994; Imbalzano et al. 1994, 1996; Kwon et al. 1994; Owen-Hughes et al. 1996; Wang et al. 1996), the Drosophila Nurf complex (Tsukiyama and Wu 1995), and the yeast RSC complex (Cairns et al. 1996) have been shown to use the energy of ATP hydrolysis to disrupt nucleosome structure and/or stimulate the binding of transcription activators to nucleosomal DNA. NURF and Swi/Snf participate in activator-dependent formation of DHSs in vitro (Tsukiyama and Wu 1995; Owen-Hughes et al. 1996) and SWI/SNF gene products have been shown to function in chromatin remodeling in vivo (Hirschhorn et al. 1992).

In addition to ATP-dependent chromatin remodeling activities, histone acetyltransferases have been impli- 
cated in transcription regulation. Numerous studies have illustrated a correlation between the acetylation of lysine residues on the amino terminal tails of the core histones and transcriptional activity of cellular chromatin (for review, see Loidl 1994; Turner and O'Neill 1995). Acetylation of core histones has been shown to enhance the affinity of transcription factors for nucleosomal DNA (Lee et al. 1993; Juan et al. 1994; Vettese-Dadey et al. 1996) and may cause a conformational change in nucleosome structure (Norton et al. 1989, 1990; Bauer et al. 1994). Two classes of histone acetyltransferases (HATs) bring about the acetylation of core histones. Cytoplasmic type B HATs acetylate free histones for subsequent assembly into chromatin (Kleff et al. 1995; Eberharter et al. 1996; Parthun et al. 1996; for review, see Roth and Allis 1996) and nuclear type A HATs bring about transcription-related acetylation of chromosomal histones (for review, see Brownell and Allis 1996). Recently, several nuclear proteins involved in transcriptional regulation have been shown to have histone acetyltransferase activity, suggesting their potential function as type A HATs. These include the transcriptional adaptor proteins Tetrahymena, yeast and human Gcn5 (Brownell et al. 1996; Kuo et al. 1996; Wang et al. 1997), human pCAF (Yang et al. 1996), human p300/CBP (Bannister and Kouzarides 1996; Ogryzko et al. 1996), and the TATA-binding protein (TBP)-associated factor, human $\mathrm{TAF}_{\mathrm{II}} 250$ and its homologs, Drosophila $\mathrm{TAF}_{\mathrm{II}} 230$, and yeast $\mathrm{TAF}_{\mathrm{II}} 130$ (Mizzen et al. 1996).

GCN5 was identified originally by genetic selections in yeast as a gene whose product interacted functionally with the transcription activator Gen4 (Georgakopoulos and Thireos 1992) and the activation domain derived from herpes simplex virus VP16 (Marcus et al. 1994). $A D A 2$ (Berger et al. 1992), ADA3 (Piña et al. 1993), and ADA5 (Marcus et al. 1996; Roberts and Winston 1996) genes were similarly identified and cloned in a selection for mutants resistant to GAL4-VP16-mediated toxicity. Mutations in GCN5, $A D A 2, A D A 3$, or $A D A 5$ all result in slow growth and reduce transcriptional activation in yeast (Berger et al. 1992; Piña et al. 1993; Marcus et al. 1996). Ada2, Ada3, and Gen5 were shown to interact physically with each other in vitro and in vivo (Marcus et al. 1994; Horiuchi et al. 1995; Candau and Berger 1996), indicating that these proteins function as members of a multiprotein complex (Ada complex). Moreover, biochemical studies have shown that Ada2 interacts directly with the activation domains of VP16 and Gcn4, and indirectly with TBP, arguing that the Ada complex may mediate interactions between acidic activators and TBP (Silvermann et al. 1994; Barlev et al. 1995).

$A D A 5$ has been found to be identical to SPT2O (Marcus et al. 1996; Roberts and Winston 1996), providing genetic evidence of functional linkage of Ada proteins with Spt proteins. SPT genes were isolated as suppressors of Ty and $\delta$ insertion mutations, and suppressor mutations in SPT genes alter transcriptional start site selection (Winston and Carlson 1992). SPT genes fall into two general classes of transcriptional regulators. One group includes genes for histones and other proteins thought to affect chromatin structure (Winston and Carlson 1992). The second group includes SPT3, SPT7, SPT8, SPT15, and SPT20, which are thought to affect TBP function (SPT15 encodes TBP itself). Mutations in these genes cause slow growth and transcription defects at particular promoters (Winston et al. 1984, 1987; Hirschhorn and Winston 1988; Eisenmann et al. 1989, 1994; Gansheroff et al. 1995; Roberts and Winston 1996). Moreover, Spt3 has been shown to interact functionally with TBP, Motl, and TFIIA, implicating Spt 3 in the regulation of transcription complex formation (Eisenmann et al. 1992; Madison and Winston 1997). The finding that genetic and biochemical similarities exist between $A D A$ and $S P T$ genes suggests that they may function in related physiological pathways.

In this report we show that, whereas recombinant Gcn5 is a potent acetyltransferase of free histones, it fails to modify histones contained within nucleosomes. However, Gen 5 functions as a catalytic subunit in two highmolecular-weight native HAT complexes that effectively acetylate nucleosomal histones. Both of these complexes also contain Ada2 and Ada3 and therefore represent native adaptor complexes. The larger complex also contains Spt3, Spt7, and Spt20/Ada5, illustrating that the HAT activity of Gen5 functions as part of an Spt/Ada complex implicated in controlling transcription complex formation (also see Roberts and Winston 1997).

\section{Results}

Gcn5 alone is unable to function as an acetyltransferase of nucleosomal histones

A novel in-gel activity assay (Brownell and Allis 1995) was exploited to purify the first nuclear type A HAT, termed p55, from Tetrahymena. Cloning of the corresponding gene revealed that it was the homolog of the yeast transcriptional adaptor protein Gen5 (Brownell et al. 1996). Since this initial finding, p55, yeast Gen5, and human Gen 5 all have been shown to possess HAT activity (Brownell et al. 1996; Kuo et al. 1996; Wang et al. 1997). Yeast Gcn 5 is a potent HAT able to modify purified histone $\mathrm{H} 3$ or $\mathrm{H} 4, \mathrm{H} 3$ and $\mathrm{H} 4$ tetramers, or a mixture of all four core histones. In the latter two instances Gen5 acetylates primarily histone $\mathrm{H} 3$, and to a lesser extent H4 (Kuo et al. 1996; J.E. Brownell, R. Candau, R. Ohba, S.L. Berger, and C.D. Allis, unpubl.). Gen5 has been shown to generate transcription-related patterns of histone acetylation (Kuo et al. 1996), furthering the notion that it functions as a type A HAT that modifies cellular chromatin. However, when Gen5 was presented with nucleosome cores as a substrate in HAT assays it did not acetylate any of the core histones (Fig. 1A, cf. lanes 2 and 6). Therefore, Gen 5 alone is unable to function as an acetyltransferase of nucleosomal histones, a result consistent with that reported for hGen5 (Yang et al. 1996). As we previously found that the in vivo function of Gen5 requires both the HAT domain and a distinct domain mediating interaction with Ada2 (Candau et al. 1997), 


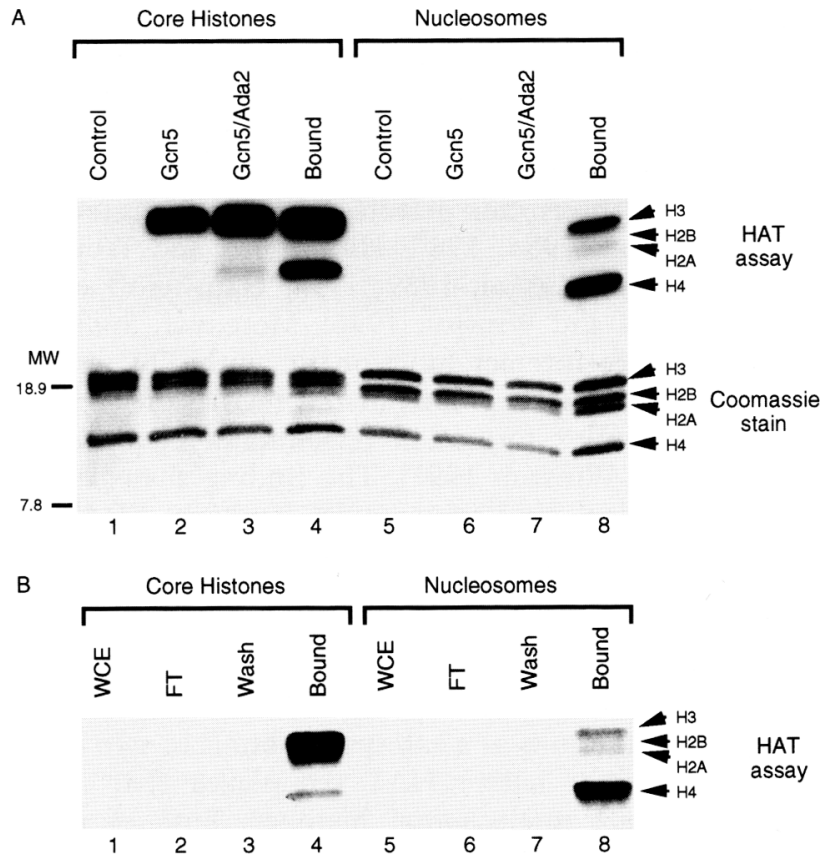

Figure 1. Native nucleosomal HAT activity from yeast extracts. (A) SDS-PAGE analysis and fluorography of acetylated histones. Renatured Gen5 or Gen5/Ada2 dimers (lanes 2,3,6,7) specifically acetylate histone $\mathrm{H} 3$ when incubated with free core histones in a HAT assay, but fail to acetylate nucleosomal histones. In contrast, native HAT activities that bind to a $\mathrm{Ni}^{2+}$ NTA agarose column (lanes 4,8 ; bound) acetylate both histones $\mathrm{H} 3$ and $\mathrm{H} 4$ in core histones and all histones to varying extents on nucleosomal substrate. (Lanes 1,5) Control HAT assays incubated in the absence of recombinant proteins or $\mathrm{Ni}^{2+}-\mathrm{NTA}$ agarose eluted fractions. The lower panel of $A$ shows the Coomassie staining of the same gel. The arrows indicate the migratory positions of the four core histones. (B) Retention of HAT activity by $\mathrm{Ni}^{2+}-\mathrm{NTA}$ agarose. Equivalent amounts $(15 \mu \mathrm{g})$ of yeast whole-cell extract (lane 1; WCE), flow-through from the $\mathrm{Ni}^{2+}$-NTA agarose column (lane 2; FT), $20 \mathrm{~mm}$ imidazole wash (lane 3; Wash), and bound proteins eluted with $300 \mathrm{~mm}$ imidazole (lane 4; bound) were incubated with core histones or nucleosomes in a HAT assay. $\mathrm{Ni}^{2+}-\mathrm{NTA}$ agarose bound HAT activities efficiently acetylated both core and nucleosomal histones.

we tested whether Ada2 might facilitate nucleosome acetylation by Gen5. Gcn5/Ada2 heterodimers efficiently acetylated free histones but were also unable to modify nucleosomal histones (Fig. 1A, lanes 3,7). Moreover, additional experiments have shown that Gcn5/ Ada2/Ada3 heterotrimers also lacked the ability to modify nucleosomal histones (data not shown; J.E. Brownell, R. Candau, R. Ohba, S.L. Berger, and C.D. Allis, unpubl.).

\section{Multiple native yeast HAT complexes acetylate distinct spectrums of nucleosomal histones}

In contrast to the inability of recombinant Gen5 to acetylate nucleosomal histones, a fraction enriched in native yeast HAT activity was able to acetylate both free histones and nucleosomal histones (Fig. 1A, lanes 4 and 8). This fraction was eluted from a Ni-agarose column, which fortuitously retains the bulk of the nucleosomal HAT activity from yeast extracts (Fig. 1B). Ni-agarose retained the HAT activities regardless of the presence of any histidine-tagged proteins. The $\mathrm{Ni}$-agarose-bound material contains HAT activities that acetylate all four core histones in nucleosomes to varying degrees.

Further fractionation of this HAT activity using ion exchange chromatography revealed that the $\mathrm{Ni}$-agarosebinding material contained four distinct native nucleosomal HAT activities (Fig. 2). Moreover, the histone preferences of these activities differ. Two HATs preferably acetylated $\mathrm{H} 3 / \mathrm{H} 2 \mathrm{~B}$ (complexes 1 and 4 ), another preferably acetylated H4/H2A HAT (complex 2), and another preferably acetylated $\mathrm{H} 3$ (complex 3). It is important to note that nucleosome cores were used as the substrate for the HAT assays shown in Figure 2 and in all the subsequent experiments [Figs. 3, 4, 5, and 6 (only the in gel assay in 4C used free histones)]. Therefore, all four of the identified HAT complexes, $1-4$, were able to acetylate nucleosomal histones, in contrast to the activity of GCN5 alone (Fig. 1).

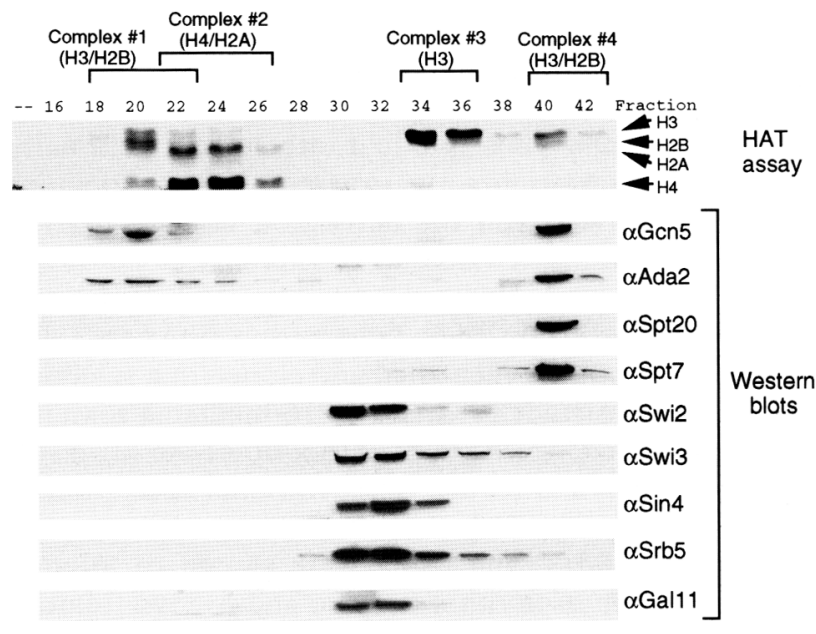

Figure 2. Separation of distinct HAT complexes that specifically acetylate different nucleosomal histones. Nucleosomal HAT assay using protein fractions from a Mono Q column run with the $\mathrm{Ni}^{2+}-\mathrm{NTA}$ agarose bound sample from Fig. 1 . Shown is a fluorograph of the HAT assay and the arrows indicate the positions of the core histones. The brackets above the lanes indicate the elution profile of the individual $\mathrm{H} 3 / \mathrm{H} 2 \mathrm{~B}$ (complexes 1 and 4), H4/H2A (complex 2), and H3 (complex 3) HAT activities. Western blots were performed with the same fractions using antisera against the yeast adaptor proteins Gcn5 and Ada2, the Spt proteins Spt20 and Spt7, the Swi/Snf complex subunits Swi2 and Swi3, and the mediator complex/RNA polymerase II holoenzyme components Sin4, Srb5, and Gal11 as indicated). The Swi/Snf and mediator proteins displayed a different elution profile from those of the HAT activities, whereas Gcn 5 and Ada2 co-elute in two peaks, overlapping the HAT complexes 1 and 4 . The Spt proteins co-elute tightly only with complex 4. 
A

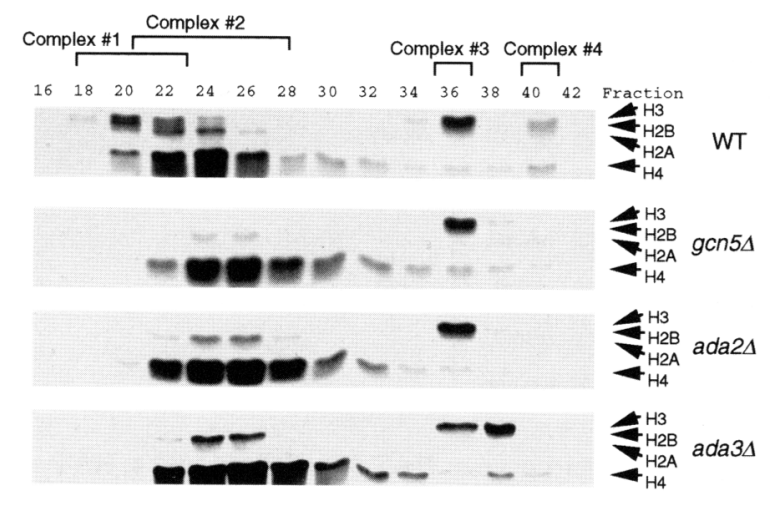

B

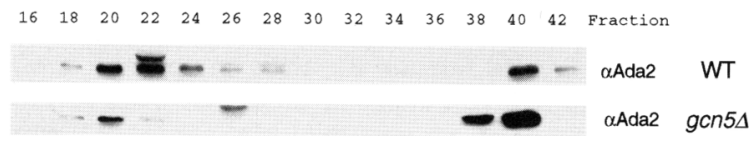

Figure 3. Yeast strains with Adaptor protein deletions are specifically defective in the complex 1 and complex 4 HAT activities. $(A)$ Fluorograph from a nucleosomal HAT assay using protein fractions from a Mono Q column prepared from wild-type

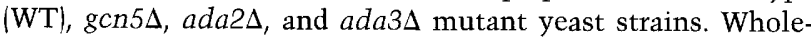
cell extracts were first bound to $\mathrm{Ni}^{2+}-\mathrm{NTA}$ agarose, eluted with $300 \mathrm{~mm}$ imidazole, and then loaded on a Mono Q column. The position of the HAT complexes 1-4 in wild-type extracts, eluted from the Mono Q column, are indicated. $(B)$ Adaptor complexes eluting from the Mono Q column fail to acetylate nucleosomal histones in the absence of Gen5. Shown is a Western blot of Mono Q fractions from wild-type (WT) and $g c n 5 \Delta$ yeast strains, probed with antiserum against Ada2.

\section{Gen5 functions as the catalytic subunit in two} distinct nucleosomal HAT complexes

To examine whether Gcn5 might function as a catalytic subunit in any of the native nucleosomal HATs, we used Western blotting to examine the elution profile of Gen5 and Ada2 from the ion exchange column to determine whether they co-eluted with the HAT activities (Fig. 2). Gcn5 and Ada2 co-eluted in two peaks across the column, overlapping with both of the $\mathrm{H} 3 / \mathrm{H} 2 \mathrm{~B}$ activities (complexes 1 and 4). Recently, genetic studies have indicated that Ada5/Spt20 functionally links Ada proteins with the TBP group of Spt proteins (Marcus et al. 1996; Roberts and Winston 1996). Therefore, we tested whether Spt proteins in the TBP class co-eluted with the Gcn5/Ada2-associated HAT activities. Using antibodies against Spt20 and Spt7, we found that these proteins coelute only with complex 4 (Fig. 2). Similar results were found using antibodies against Spt 3 (data not shown), suggesting that the products of the $A D A$ and TBP class of $S P T$ genes physically associate in a novel nucleosomal HAT complex.

Because the Swi/Snf complex is involved in chromatin remodeling related to gene activation (Côté et al. 1994), we tested for any interaction between SWI/SNF and the
HAT activities. Immunoblot analysis indicated that none of the HAT complexes co-elute with the Swi2 or Swi3 subunits of the Swi/Snf complex (Fig. 2). We also tested for any physical interaction between the HAT complexes and the mediator/holo RNA polymerase complex. Neither the Sin4, Srb5, or Gall1 components of the mediator/holoenzyme complex (Koleske and Young 1994; Li et al. 1995), co-eluted with the HAT complexes. Therefore, the HAT activities are clearly chromatographically distinct from these multiprotein transcriptional regulators described previously.

In vivo function of Gen5 required its domain of Ada2 interaction (Candau et al. 1997), therefore we tested whether the $A D A$ gene products are required for the integrity of the two $\mathrm{H} 3 / \mathrm{H} 2 \mathrm{~B}$ HAT activities (complexes 1 and 4). Extracts were prepared from wild-type and isogenic strains bearing disruptions of GCN5, $A D A 2$, or $A D A 3$. Although the wild-type extracts had an elution profile from the Mono Q ion exchange column similar to those of extracts from the CY396 strain (Fig. 2), extracts prepared from $g c n 5 \Delta, a d a 2 \Delta$, or ada $3 \Delta$ yeast strains were specifically lacking complexes 1 and 4, the two $\mathrm{H} 3 / \mathrm{H} 2 \mathrm{~B}$ HAT activities (see fractions 20 and 40 of Fig. 3A). In contrast, HAT complexes 2 and 3 were unaffected by gcn5 5 , ada2s, or ada3 $\Delta$ mutations (see fractions 24 and 36, Fig. 3A). This result substantiates evidence that Ada2, Ada3, and Gen5 interact with each other in vitro (Horiuchi et al. 1995) and in vivo (Candau and Berger 1996) and provides biochemical evidence that interactions of the Ada proteins are required for the activity of these two native HATs, consistent with our previous genetic evidence that interaction with Ada2 is mandatory for function of the HAT domain of Gen5 in vivo (Candau et al. 1997). In the absence of Gen5, Ada2-containing complexes (complexes 1 and 4) were still detected in fractions eluting from the Mono Q column, albeit altered slightly in their elution profiles (Fig. 3B). However, these Gcn5-deficient Ada complexes were unable to acetylate nucleosomal histones (Fig. 3A). The fact that complexes 1 and 4 were still present in the absence of Gcn5 but unable to acetylate nucleosomal histones provides compelling evidence that Gen5 is the primary catalytic subunit of these native nucleosomal HAT complexes.

To test further for co-purification of HAT activity with Gen5 and Ada2, and to determine the sizes of the two Ada-HAT complexes, a pool of peak fractions from the Mono Q column for each Ada-HAT was fractionated further by gel filtration chromatography on a Superose 6 column. Nucleosomal HAT complex 1 eluted from the Superose 6 column as a large complex of $\sim 800 \mathrm{kD}$ (Fig. 4A). This complex tightly cofractionated with Gcn5 and Ada2, as determined by Western blotting. Nucleosomal HAT complex 4 eluted as a larger complex of $\sim 1.8 \mathrm{MD}$ and also cofractionated with Gen 5 and Ada2 (Fig. 4B). In addition, this HAT was found to tightly co-elute with the Spt proteins Spt3, Spt7, and Spt20 (Fig. 4B; see, also below).

The cofractionation of Gen 5 with complexes 1 and 4, the two H3/H2B nucleosomal HATs, (Fig. 4A,B) and the 
A

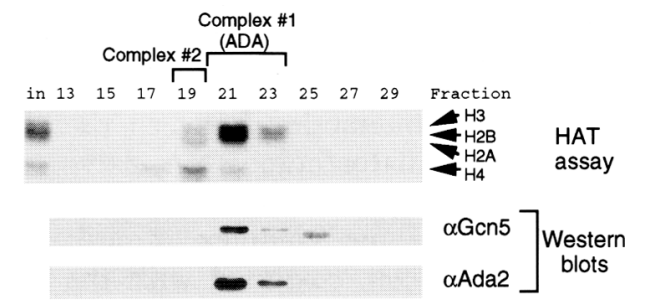

C

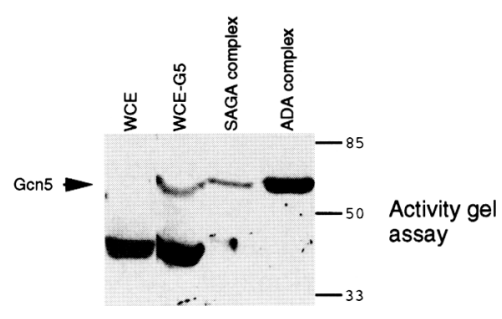

B

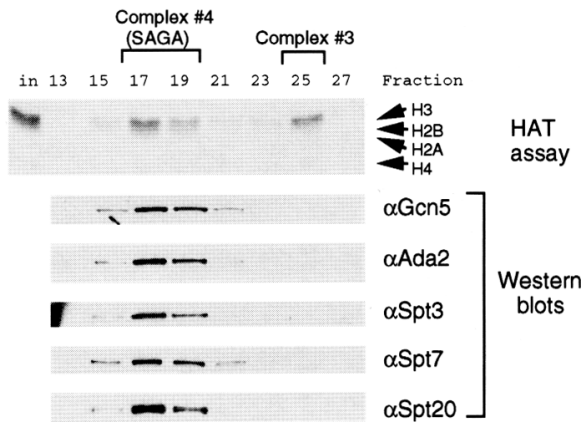

Figure 4. Size fractionation of the native yeast HAT complexes 1 and 4. HAT assays and Western blots of Superose 6 fractions $(A)$. Fluorograph of HAT assays using nucleosome cores incubated with the gel filtration chromatographed fractions of complex 1. Western blots of $20 \mu \mathrm{l}$ of the Superose 6 fractions with antisera against Gcn 5 and Ada2 proteins indicate that these proteins co-elute with complex 1 (ADA) HAT activity, discretely peaking around fraction 21 , with an apparent molecular mass of $0.8 \mathrm{MD}$. Some contaminating complex 2 activity is evident in fraction 19 (with an apparent molecular mass of $1.3 \mathrm{MD}$ ), presumably attributable to the close elution profile of these two complexes on the Mono Q column. (B) Nucleosomal HAT assay and Western blots using Superose 6 fractions from the complex 4 (SAGA) column. Gcn5, Ada2, Spt3, Spt7, and Spt20 co-elute with this HAT activity, discretely peaking around fraction 17 , with an apparent molecular mass of $1.8 \mathrm{MD}$. Some contaminating complex $3 \mathrm{HAT}$ activity is evident in fraction 25 (with an apparent molecular mass of $\sim 0.5 \mathrm{MD}$ ). (C) Gel activity assay indicates that Gen5 is the predominant catalytic subunit of the two H3/H2B complexes. Samples corresponding to yeast whole-cell extract (WCE), whole-cell extract of cells expressing recombinant Gcn5 (WCE-G5), and peak Superose 6 fractions of the 0.8-MD Ada complex and 1.8-MD SAGA complex were electrophoresed in a $10 \%$ SDS-polyacrylamide gel and inspected for HAT activity using the activity gel assay. Shown is a fluorograph of ${ }^{3} \mathrm{H}$-labeled acetate incorporation into histones. The migratory position of protein molecular weight standards is shown beside the flourograph.

loss of their respective activity in $g c n 5 \Delta$ (Fig. 3), indicates that Gen 5 is a primary catalytic subunit of these complexes. To confirm the presence of Gcn5 as the HAT activity in these complexes, we used an in-gel activity assay (Brownell and Allis 1995). This assay uses free histones as substrates within polyacrylamide gels and has the potential to detect any polypeptide with HAT activity. For example, the strong activity migrating $\sim 40 \mathrm{kD}$ from whole-cell yeast extracts in the first two lanes of Figure $4 \mathrm{C}$ is presumably Hat 1 , which acetylates free histones but does not acetylate nucleosomal histones (Parthun et al. 1996). Using this assay we identified the HAT activity in the peak Superose 6 fractions of both of these HAT complexes as a protein with an apparent molecular mass of $55 \mathrm{kD}$, which comigrated with Gen5 overexpressed in yeast extracts (Fig. 4C). Therefore, nucleosomal histone acetylation by the Ada and Ada/Spt (SAGA) HAT complexes required the presence of Gcn5 (Fig. 3), and Gcn5 was the only HAT activity detected in these complexes. Taken together, these results demonstrate for the first time the function of Gcn5 as a nucleosomal HAT (i.e., a type A HAT). Moreover, the function of Gcn5 as a nucleosomal HAT required its presence within these native Ada and Ada/Spt HAT complexes, where it is the primary catalytic subunit.

The SAGA complex contains both ADA and SPT gene products

The cofractionation of Gcn5 and Ada2 with Spt3, Spt7, and Spt20 in the 1.8-megadalton (MD) complex 4 (Figs. 2 and 4) suggests that these Ada proteins and the TBP group of Spt proteins are an integral part of a native complex containing gene products implicated in mediating the function of transcription activators and in facilitating transcription complex formation (see Introductory section). Therefore, this complex appears to represent a novel native Spt/Ada HAT complex, which we have named SAGA (Spt-Ada-Gcn5-acetyltransferase). To demonstrate further the association of these two distinct protein groups in a unique complex, we further purified the SAGA complex over an additional five columns (Fig. 5A). We found continued co-fractionation of the SPT and $A D A$ gene products with the HAT activity of this complex over these subsequent columns. Figure 5B shows the tight co-elution of HAT activity with Gcn5, Ada2, Spt3, Spt7, and Spt20 from the Mono S cation exchange column, illustrating the co-purification of these proteins with the HAT complex (Fig. 5B). In contrast, whereas there is genetic and biochemical data indicating an interaction of Ada and Spt proteins with TBP /Eisenmann et al. 1992, 1994; Barlev et al. 1995; Madison and Winston 1997; Roberts and Winston 1997; Saleh et al. 1997), we have not detected TBP by Western blotting in the SAGA complex (data not shown). It is interesting to note that the SAGA complex may also weakly acetylate nucleosomal histone $\mathrm{H} 4$ (fractions 38 and 40 of Fig. 5B). Such activity is consistent with the fact that recombinant Gen 5 has been shown to acetylate histone $\mathrm{H} 4$, but to a much lesser extent than H3 (Brownell et al. 1996; Kuo et al. 1996).

Figure 5C shows the protein profile of the SAGA-con- 
A

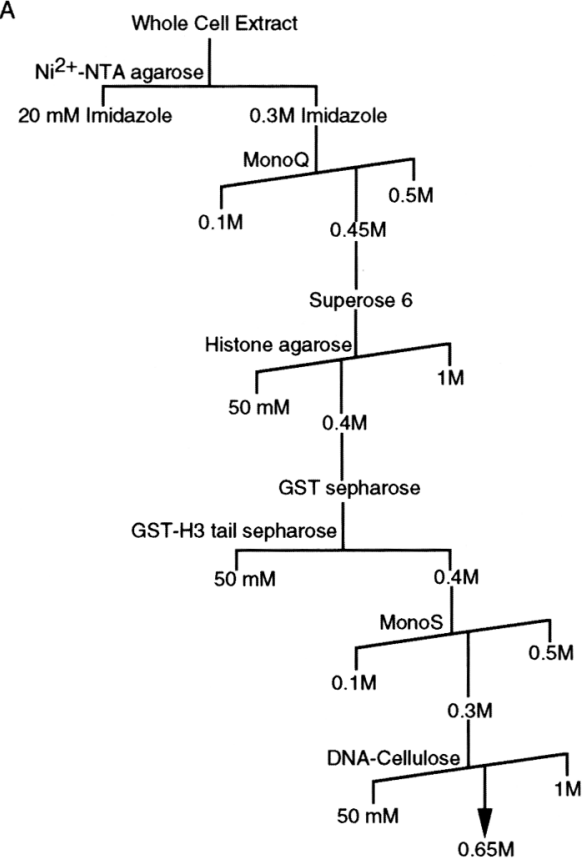

B

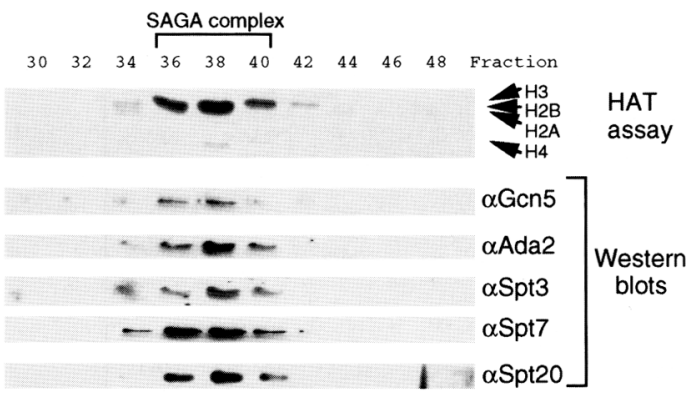

C

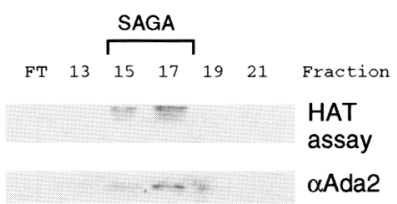

Spt7

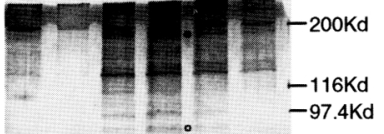

Silver stain

Figure 5. Purification of the yeast SAGA complex. (A) Purification scheme for the 1.8-MD nucleosomal HAT complex, SAGA. (B) Nucleosomal HAT assay and Western blots using purified SAGA protein fractions from the Mono $S$ column. Both the adaptor proteins Gcn5 and Ada2 and Spt proteins Spt3, Spt7, and Spt20 were found to copurify with the acetyltransferase activity. (C) HAT assay, Western blot, and silver stain gel using the SAGA protein fractions eluted from the final DNA-cellulose column. (0) The predicted migratory positions of the Spt7, Spt20, Gen5, Ada2, and Spt3 proteins as determined by Western blotting; (O) the migratory positions of polypeptides with the predicted molecular masses of the Ada3 and Spt8 proteins implicated as part of the SAGA complex.

taining fractions from the 8th column, DNA cellulose. The elution of the SAGA complex (fractions 15-17) was identified by HAT assay and by Western blots with Ada2 antibodies. We estimate the SAGA complex to be $\sim 70 \%$ pure in these fractions. As expected from the large size of the complex, 1.8 MD, there were numerous polypeptides in the most pure fractions. Importantly, many of these appear to be present in similar amounts. These include polypeptides of the predicted molecular masses of $\mathrm{Spt} 7$, Spt20, Gcn5, Ada2, and Spt3 (filled dots in Fig. 5C), which copurified with the SAGA complex (Fig. 5B). Also present in apparently equal stoichiometry are polypeptides with the predicted molecular masses of Ada3 and Spt8 (Fig. 5C, open dots), suggesting the presence of these proteins in the SAGA complex. This is consistent with the fact that the SAGA complex is dependent on the presence of Ada3 (Fig. 3) and with reports indicating the association of Ada3 with Ada2 and Gcn5 (Horiuchi et al. 1995; Saleh et al. 1997); and the association of Spt8 with Spt7, Spt3, and Spt20/Ada5 (Roberts and Winston 1997).

To confirm the presence of SPT gene products in the SAGA complex, we prepared extracts from isogenic wild-type, spt20s, and spt7s yeast strains and fractionated these through the Mono Q column to identify the SAGA complex. Although both HAT complexes 1 (Ada) and 4 (SAGA) were identified from the wild-type extracts,

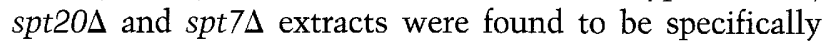
deficient in only complex 4 (i.e., the SAGA complex) (Fig. 6). Furthermore, both the Gcn 5 and Ada2 proteins co-eluting with the SAGA activity in the wild-type strain were absent in the spt20 $\Delta$ and $s p t 7 \Delta$ yeast strains. A similar result was found with Western blots using antisera against

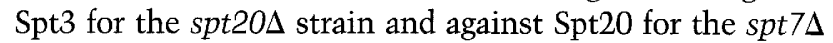
strain (data not shown). In contrast, the Ada complex (complex 1) was apparently unaffected by the deletion of the SPT20 or SPT7 genes (Fig. 6). Importantly, expression levels

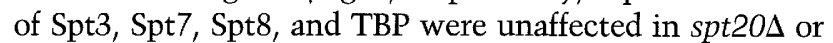
gcn5 $\Delta$ strains, when compared with wild type (S.M. Roberts and F. Winston, unpubl.), suggesting that these SPT genes are not directly dependent on $A D A$ gene products for their expression. Collectively, these results indicate that the expression of both $A D A$ and SPT family members are independently required for the presence and activity of the SAGA complex. 


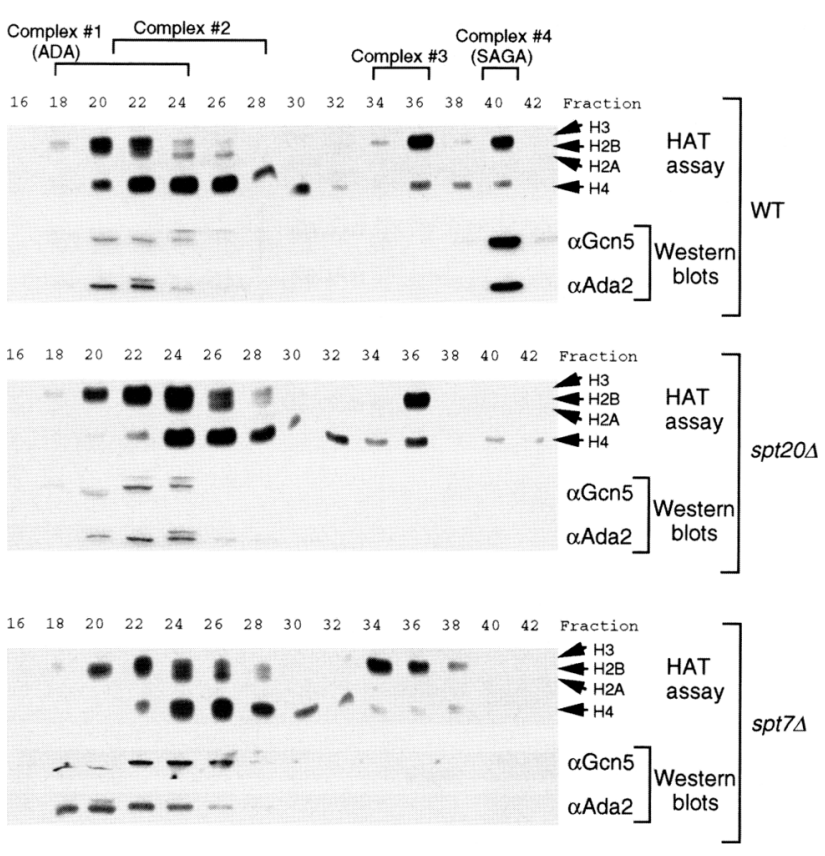

Figure 6. Yeast strains with $\mathrm{Spt}$ protein deletions are specifically defective in the SAGA (complex 4) nucleosomal HAT activity. Nucleosomal HAT assays and Western blots using protein fractions from a Mono Q column prepared from wild-type (WT), spt20 $\Delta$ and spt $7 \Delta$ mutant yeast strain. Whole-cell extracts were first bound to $\mathrm{Ni}^{2+}-\mathrm{NTA}$ agarose, eluted with $300 \mathrm{~mm}$ imidazole, and then loaded on a Mono Q column. The adaptor complex associated with the complex 1 activity, eluting from the Mono Q column, is apparently unaffected by the deletion of SPT20 or SPT7. In contrast, the complex 4 nucleosomal HAT

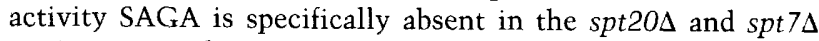
strains, as are the associated Gen 5 and Ada2 proteins.

\section{Discussion}

Gcn5 function as a type A HAT requires association into multisubunit native HAT complexes

A long history of investigations have provided striking correlations between the presence of acetylated lysine residues in the core histone amino termini and the transcriptional activity of corresponding chromosomal genes (Loidl 1994; Turner and O'Neill 1995). The observation that there are multiple nucleosomal HATs in yeast (López-Rodas et al. 1991), which acetylate different spectrums of core histone substrates may contribute to the apparent distinct functions of the different core histone amino-terminal tails in transcription activation and repression revealed by genetic studies (Durrin et al. 1991; Mann and Grunstein 1992; Thompson et al. 1994; Fisher-Adams and Grunstein 1995). Modification of different histone tails may perform unique functions in reducing interactions of nucleosomes with transcriptional repressors (Hecht et al. 1995; Edmondson et al. 1996) and in enhancing interactions with transcriptional activators (Vettese-Dadey et al. 1996) and basal transcription factors (Imbalzano et al. 1994).

The discovery that the transcriptional adaptor protein
Gcn 5 functions as a HAT (Brownell et al. 1996) provided a direct link between the process of transcription activation and histone acetylation. Functional studies have localized the HAT domain, and have shown that it is required for in vivo function of Gen5 (Candau et al. 1997; Wang et al. 1997). However, the potential function of Gcn5 as a type A HAT appears to require additional activities. Although purified Gen5 is a potent acetyltransferase of free histones it lacks the ability to access and/or modify core histones associated with DNA in the form of nucleosomes, the expected relevant substrate for a nuclear type A HAT. In this report we demonstrate that yeast Gen5 does function as a type A HAT but only within the context of native multisubunit high-molecular-weight complexes. Therefore, one crucial function of the two complexes described here is to bestow on Gen 5 the ability to modify histones contained within pre-assembled nucleosome cores. This activity supports a role of Gen5 in modifying pre-existing chromatin during alterations of chromatin structure that accompany transcription activation (for review, see Brownell and Allis 1996; Steger and Workman 1996).

\section{The Gcn5-containing HAT complexes are Ada transcriptional "adaptor" complexes}

The experiments presented in this report demonstrate that the two native Gcn5-containing HAT complexes also contain and are dependent on the products of the $A D A 2$ and $A D A 3$ genes. This provides a biochemical explanation for our previous observation that Gen5 requires both its HAT domain and its Ada2-interaction domain for in vivo function (Candau et al. 1997). The presence of Ada proteins in the HAT complexes with Gen5 indicates another potential function of the complexes. Biochemical interactions have been described between Ada2 and certain acidic transcriptional activators as well as TBP (Silvermann et al. 1994; Barlev et al. 1995; Melcher and Johnston 1995) and between Ada2 and Gcn5 with the transcriptional activator Adrl (Chiang et al. 1996), illustrating a pathway by which the Ada-HAT complexes might be recruited to specific genes during transcription activation.

We estimate the molecular masses of these HAT complexes as 1.8 and $0.8 \mathrm{MD}$. These Ada complexes are likely to correspond to the large Ada3- and Ada2-containing complexes from yeast, independently identified by C.L. Brandl and colleagues, with estimated molecular masses of 2 and $0.9 \mathrm{MD}$ (Saleh et al. 1997). These authors also identified a smaller Ada3- and Ada2-containing complex of $200 \mathrm{kD}$ that is similar in size to a Tetrahymena type A HAT of $220 \mathrm{kD}$ purified by Brownell and Allis (1995). Therefore, it is likely that there is at least one additional Ada-Gcn5 complex in yeast that is smaller than those described here. The potential function of this yeast complex in nucleosomal histone acetylation and its relationship to the larger complexes has not been determined.

The relationship between the $0.8 \mathrm{MD}$ Ada-HAT complex and the 1.8-MD SAGA complex is not yet clear. 
Both complexes contain Gen5 as the catalytic HAT subunit as well as Ada2 and Ada3. One possibility is that the 0.8-MD Ada-HAT complex lacks the Spt gene products, and is a subcomplex of the larger SAGA complex. In this case, because both complexes acetylate common nucleosomal histones, it is probable that the smaller complex contains all components necessary for recognition, interaction, and catalytic acetylation of nucleosomal histones. The larger complex would then likely possess additional attributes, conferred by the Spt proteins. An alternative possibility is that, although both contain Gen5 and Ada proteins, each complex might represent quite distinct nucleosomal HAT activities with unique functions. Therefore, the additional components would dictate the physiological role of the HAT, for example, which promoter might be affected, and how the HAT activity is regulated. The exact relationship between these two HAT complexes will be clarified on identification of the unknown subunits of each complex and the degree to which they are common or unique. It is important to emphasize, however, that each of these Ada-HAT complexes is chromatographically distinct from the Swi/ Snf and the mediator complexes. Therefore, the high molecular weight of these HAT complexes does not result from any association of Gcn 5 and Ada proteins with either of these multisubunit transcription regulatory complexes characterized previously.

\section{The SAGA complex links the function of Spt gene products with Ada proteins and histone acetylation}

A recent report demonstrated that a null mutation in $S P T 20$, like those of $S P T 3, S P T 7$, or $S P T 8$ resemble certain misense mutations in the gene encoding TBP, SPT15 (Roberts and Winston 1996). Because these genes do not appear to regulate each other's transcription (Winston et al. 1987, S.M. Roberts and F. Winston, unpub1.|, the similar mutant phenotypes suggest that Spt3, Spt7, Spt8, and Spt20 are required for normal TBP function at certain promoters. In a study related to this work, S.M. Roberts and F. Winston report Gst-Spt20 interactions with Spt7, Spt8, Spt3, and TBP (Roberts and Winston 1997). SPT20 is the same gene as ADA5, and shares mutant phenotypes with both $S P T$ and $A D A$ groups of genes (Marcus et al. 1996; Roberts and Winston 1996). Together these genetic and biochemical studies suggest that Spt3, Spt7, Spt8, and Spt20 may function in a single complex to regulate TBP function and also interact with the $A D A$ group of gene products. Identification of the SAGA complex in this report demonstrates the existence of an Spt/Ada protein complex linking the function of these Spt proteins to histone acetylation by Gen5.

The SAGA complex represents a novel transcription regulatory complex that bears the hallmarks of a transcriptional "adaptor" or "co-activator" complex. It contains proteins that have been implicated by genetic and biochemical studies as interacting with acidic activation domains (i.e., Ada2; Silvermann et al. 1994; Barlev et al. 1995), as well as TBP (i.e., Ada2, Spt3, and Spt20; Eisenmann et al. 1992, 1994; Barlev et al. 1995; Madison and
Winston 1997; Roberts and Winston 1997). Genetic analysis suggests that the SAGA complex might perform multiple functions in transcription activation (Roberts and Winston 1997). These functions include nucleosomal histone acetylation by the Gen 5 subunit, which has the potential to stabilize the binding of activators and TBP to nucleosomal DNA (Lee et al. 1993; Imbalzano et al. 1994; Juan et al. 1994; Vettese-Dadey et al. $1994,1996)$ and thereby facilitate the formation of transcription complexes within chromatin. The function of Gen5 as a nucleosomal HAT within the SAGA complex implicates an important role of histone acetylation in transcription activation that is supported by the fact that the HAT domain of Gen 5 is required for GCN5 function in vivo (Candau et al. 1997).

\section{Materials and methods}

Yeast strains

The yeast strain CY396 (swi24::HIS3 HO-lacZ SWI2-HA-6HI$S:: U R A 3)$ containing a SWI2 fusion gene with a hemagglutinin (HA) epitope tag and six tandem histidines is as described (Peterson et al. 1994). The yeast strain PSY316 (MATo ade2-101 Shis3-200 leu2-3, 112 lys2 ura3-52 (Berger et al. 1992) and its derivatives PSY316 $\triangle a d a 2$ (Candau and Berger 1996), PSY316 ggcn5 (Candau et al. 1996), and PSY316 Aada3 (Piña et al. 1993) have been described previously. The $S P T^{+}$yeast strain

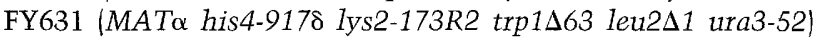
and the derivative spt20 null strain FY1095 and spt7 null strain FY963 are described (Roberts and Winston 1996).

\section{Cloning and expression of GCN5 and ADA2}

Saccharomyces cerevisiae GCN5 was expressed in bacteria as a fusion protein with six histidine residues at the amino terminus and purified on $\mathrm{Ni}^{2+}-\mathrm{NTA}$ agarose (Candau et al. 1996). yADA2 coding sequence bearing $B g l I I$ ends was amplified by PCR. The DNA fragment, digested with $B g I I I$, was ligated into the $B a m H I$ site of pRSETC (Invitrogen), which contains the six histidine residues fused to the amino terminus. pRSETC-yADA2 was transformed into JM109 cells and induced with $1 \mathrm{mM}$ IPTG and M13/T7 phage (using the XPRESS System, Invitrogen). yAda2 protein was purified subsequently on $\mathrm{Ni}^{2+}-\mathrm{NTA}$ agarose (Qiagen) under denaturing conditions (XPRESS System, Invitrogen). The Gcn5/Ada2 dimers were prepared as follows. Purified Gen5 (Candau et al. 1996) and purified Ada2 were combined and stepdialyzed against buffer /containing $10 \mathrm{~mm}$ Tris at $\mathrm{pH} 8.0,20 \%$ glycerol, $1 \mathrm{~mm}$ EDTA, $5 \mathrm{~mm} \mathrm{MgCl}, 100 \mathrm{~mm} \mathrm{NaCl}, 5 \mathrm{~mm}$ 2-mercaptoethanol| to remove urea. Titrated amounts of the dimer and purified Gen 5 were compared quantitatively in Western blot probed with Gen5 antisera (Candau et al. 1996).

\section{Histone and nucleosome purification}

HeLa core histones and oligonucleosomes were isolated as described (Côté et al. 1995). Chicken histones were prepared from chicken blood (a kind gift from Dr. Guy Barbato, Pennsylvania State University, University Park) by acid extraction as described (Workman et al. 1991).

\section{HAT assays}

Liquid HAT assays were performed as follows; $1 \mu \mathrm{g}$ of core histones or oligonucleosome cores were incubated together 
with bacterially expressed Gcn5, Gcn5/Ada2 dimers, or yeast extract chromatographed fractions and ${ }^{3} \mathrm{H}$-labeled acetyl-CoA $\{0.125 \mu \mathrm{Ci})$ in HAT buffer $(50 \mathrm{~mm}$ Tris- $\mathrm{HCl}$ at $\mathrm{pH} 8.0,50 \mathrm{~mm}$ $\mathrm{KCl}, 5 \%$ glycerol, $0.1 \mathrm{~mm}$ EDTA, $1 \mathrm{~mm}$ DTT, $1 \mathrm{~mm}$ PMSF, 10 $\mathrm{mM}$ sodium butyrate) at $30^{\circ} \mathrm{C}$ for $30 \mathrm{~min}$. The reactions were then subjected to SDS-polyacrylamide gel electrophoresis (PAGE). All gels were Coomassie stained to ensure loading of equivalent amounts of histone in each lane, destained and flourographed with Enhance (DuPont NEN).

Approximately $20 \mu \mathrm{l}$ of Superose fractions of the two $\mathrm{H} 3 / \mathrm{H} 2 \mathrm{~B}$ HAT activities and $3 \mu \mathrm{l}$ of yeast whole-cell extract or extract from cells expressing Gcn 5 from a yeast expression vector (Candau et al. 1996) were loaded onto a 10\% SDS-polyacrylamide gel containing $0.5 \mathrm{mg} / \mathrm{ml}$ of chicken histones and subjected to an activity gel assay (Brownell and Allis 1995).

\section{Purification of HAT complexes}

Whole-cell yeast extracts were prepared from 20 liters of yeast strain CY396 as described for the Swi/Snf complex (Côté et al. 1994). Subsequent fractionation steps were modified as follows. The 160-ml extract was bound batchwise with $20 \mathrm{ml}$ of $\mathrm{Ni}^{2+}$ NTA agarose (Qiagen). The resin was then washed in a column with extraction buffer and $20 \mathrm{~mm}$ imidazole, followed by elution of the bound proteins with $300 \mathrm{~mm}$ imidazole. The NiNTA agarose column eluate was loaded directly onto a Mono Q HR $5 / 5$ column (Pharmacia). Bound proteins were eluted with a $25-\mathrm{ml}$ linear gradient of $100-500 \mathrm{ml}$ of $\mathrm{NaCl}$. One microliter of each $0.5-\mathrm{ml}$ fraction was tested for nucleosomal HAT activity. Peak fractions from the Mono Q column for complexes 1 and 4 (see Fig. 2) were pooled separately and concentrated down to 0.3 $\mathrm{ml}$ using Centriprep-30 (Amicon). Samples were then loaded on a Superose 6 HR 10/30 column (Pharmacia) in extraction buffer $(350 \mathrm{~mm} \mathrm{NaCl})$. Fractions $(0.5 \mathrm{ml})$ were aliquoted after addition of $50 \mu \mathrm{g} / \mathrm{ml}$ of insulin, frozen in liquid nitrogen and stored at $-80^{\circ} \mathrm{C}$. The Superose 6 calibration in the same buffer is as follows: exclusion volume (blue dextran), fraction 12; thyroglobulin $(669 \mathrm{kD})$, fraction 22 ; ferritin $(440 \mathrm{kD})$, fraction 26 ; adolase (158 kD), fraction 29; ovalbumin (45 kD, fraction 32). Purified Swi/Snf complex (1.5-2 MD) peaks in fraction 17 in these conditions.

Peak superose fractions of the complex 4 (SAGA) HAT (see Fig. 4) were pooled and diluted to $50 \mathrm{~mm} \mathrm{NaCl}$ and loaded directly onto a $0.5-\mathrm{ml}$ histone agarose column (Sigma). Bound proteins were eluted with a $5-\mathrm{ml}$ linear gradient of $50 \mathrm{~mm}$ to 1 $\mathrm{M} \mathrm{NaCl}$. GST and GST-H3 amino-terminal (amino acids 1-46) fusion gene plasmids are as described (Hecht et al. 1995) Approximately $2.5 \mathrm{mg}$ of GST or GST-H3 tail proteins prepared from 1 liter of Escherichia coli culture were crosslinked to 0.5 $\mathrm{ml}$ of Glutathione Sepharose 4B resin (Pharmacia). Peak fractions of the SAGA HAT activity from the histone agarose column were pooled and diluted to $50 \mathrm{~mm} \mathrm{NaCl}$ and loaded onto the GST-Glutathione Sepharose 4B resin in a column. The column was washed with $0.5 \mathrm{ml}$ of $50 \mathrm{mM} \mathrm{NaCl}$ buffer and the flowthrough was collected and loaded directly onto the GST-H3 tail Glutathione Sepharose 4B column. Bound proteins were eluted from the resin with $5 \mathrm{ml}$ of $400 \mathrm{mM} \mathrm{NaCl}$ buffer. Peak fractions from the $\mathrm{H} 3$ tail column were diluted to $100 \mathrm{mM} \mathrm{NaCl}$ and loaded onto a Mono S HR 5/5 column (Pharmacia). Bound proteins were eluted with a $10-\mathrm{ml}$ linear gradient of $100-500$ $\mathrm{mM} \mathrm{NaCl}$. Peak fractions from the Mono $S$ column were pooled and diluted to $50 \mathrm{~mm}$ and loaded onto a $0.8-\mathrm{ml}$ DNA cellulose column (Sigma). Bound proteins were eluted with an $8-\mathrm{ml}$ linear gradient of $50 \mathrm{~mm}$ to $1 \mathrm{M} \mathrm{NaCl}$. Fractions $(0.25 \mathrm{ml})$ were aliquoted and frozen in liquid nitrogen and stored at $-80^{\circ} \mathrm{C}$.

Whole-cell extracts were prepared from 4 liters of all other yeast strains, bound to $\mathrm{Ni}^{2+}-\mathrm{NTA}$ agarose and eluted with 300 mM imidazole. The eluate was loaded onto a Mono Q column and eluted as described above.

\section{Western blotting}

For Western blotting, typically $10 \mu \mathrm{l}$ of each fraction was electrophoresed on a $10 \%$ SDS-PAGE gel, transferred to nitrocellulose and processed for immunoblotting. Western blots were performed with antisera raised in rabbits against gel-purified Spt 20 and yGcn5 (Candau et al. 1996) and yAda2 six-histidine fusion proteins. Ada2 and Spt20 (amino acids 15-166) antiserum were raised at Cocalico Biologicals, Inc. (Reamstown, PA). Spt20 antisera was first passed over a Gst affinity column and then purified over an affinity column of Gst-Spt20 coupled to activated Affi-Gel15 (Bio-Rad Laboratories). Coupling and purification were performed exactly as described (Gansheroff et al. 1995). Antisera against Spt7 are as described (Gansheroff et al. 1995). Polyclonal antisera against full-length $\mathrm{Spt} 3$ protein were raised in rabbits (B.L. Berg and F. Winston, unpubl.). A monoclonal antibody to the HA epitope (12CA5; Boehringer Marnheim) was used to detect the Swi2-HA fusion protein expressed in the CY396 yeast strain and the antibodies to Swi3 are described (Peterson et al. 1994).

\section{Acknowledgments}

We thank Dr. Brad Cairns for suggesting the name SAGA. Polyclonal rabbit antisenum against Swi3, Gal11, Sin4, and Srb5 were kind gifts from Drs. C. Peterson, T. Fukasawa, D.J. Stillman, and R.A. Young, respectively. We thank Dr. S. Buratowski for TBP antibodies, Dr. M. Grunstein for the GST-H3 expression plasmid, Dr. G. Barbato for chicken blood, and Dr. C. Brandl for communicating results before publication. This work was supported by grants from the National Institute of General Medical Sciences (NIGMS) and the National Science Foundation (NSF) to J.L.W., grants from NSF and The Council for Tobacco Research to S.L.B., and National Institutes of Health (NIH) grant GM45720 to F.W. and GM53512 to C.D.A. An NIH Cancer Core training grant to the Wistar Institute supported L.D. J.C. is a Centennial Fellow of the Medical Research Council of Canada. T.O.H. was the recipient of an European Molecular Biology Organization (EMBO) long-term fellowship and is currently the recipient of Leukemia Society Special Fellowship. S.L.B is the recipient of an American Cancer Society (ACS) Junior Faculty Research Award and J.L.W. is a Leukemia Society Scholar.

The publication costs of this article were defrayed in part by payment of page charges. This article must therefore be hereby marked "advertisement" in accordance with 18 USC section 1734 solely to indicate this fact.

\section{References}

Bannister, A.J. and T. Kouzarides. 1996. The CBP co-activator is a histone acetyltransferase. Nature 384: 641-643.

Barlev, N.A., R. Candau, L. Wang, P. Darpino, N. Silverman, and S.L. Berger. 1995. Characterization of physical interactions of the putative transcriptional adaptor, $\mathrm{ADA} 2$, with acidic activation domains and TATA-binding protein. J. Biol. Chem. 270: 19337-19344.

Bauer, W.R., J.J. Hayes, J.H. White, and A.P. Wolffe. 1994. Nucleosome structural changes due to acetylation. J. Mol. Biol. 236: 685-690.

Berger, S.L., B. Pina, N. Silverman, G.A. Marcus, J. Agapite, J.L. 
Reigier, S.J. Triezenberg, and L. Guarente. 1992. Genetic isolation of ADA2: A potential transcriptional adaptor required for function of certain acidic activation domains. Cell 70: 251-265.

Brownell, J.E. and C.D. Allis. 1995. An activity gel assay detects a single, catalytically active histone acetyltransferase subunit in Tetrahymena macronuclei. Proc. Natl. Acad. Sci. 92: 6364-6368.

- 1996. Special HATs for special occasions: Linking histone acetylation to chromatin assembly and gene activation. Curr. Opin. Genet. Dev. 6: 176-184.

Brownell, J.E., J. Zhou, T. Ranalli, R. Kobayashi, D.G. Edmondson, S.Y. Roth, and C.D. Allis. 1996. Tetrahymena histone acetyltransferase A: A homolog to yeast Gcn5p linking histone acetylation to gene activation. Cell 84: 843-851.

Cairns, B.R., Y. Lorch, Y. Li, M. Zhang, L. Lacomis, H. Erdjument-Bromage, P. Tempst, J. Du, B. Laurent, and R.D. Kornberg. 1996. RSC, an essential, abundant chromatin-remodelling complex. Cell 87: 1249-1260.

Candau, R. and S.L. Berger. 1996. Structural and functional analysis of yeast putative adaptors: Evidence for an adaptor complex in vivo. I. Biol. Chem. 271: 5237-5245.

Candau, R., P.A. Moore, L. Wang, N. Barlev, C.Y. Ying, C.A. Rosen, and S.L. Berger. 1996. Identification of functionally conserved human homologs of the yeast adaptors ADA2 and GCN5. Mol. Cell. Biol. 16: 593-602.

Candau, R., J.-X. Zhou, C.D. Allis, and S.L. Berger. 1997. Histone acetyltransferase activity and interaction with ADA2 are critical for GCN5 function in vivo. EMBO I. 16: 555-565.

Chiang, Y.-C., P. Komarnitsky, D. Chase, and C.L. Denis. 1996. ADR1 activation domains contact the histone acetyltransferase GCN5 and the core transcriptional factor TFIIB. I. Biol. Chem. 271: 32359-32365.

Côté, J., J. Quinn, J.L. Workman, and C.L. Peterson. 1994. Stimulation of GAL4 derivative binding to nucleosomal DNA by the yeast SWI/SNF complex. Science 265: 53-60.

Côté, J., R.T. Utley, and J.L. Workman. 1995. Basic analysis of transcription factor binding to nucleosomes. Methods Mol. Genet. 6: 108-129.

Durrin, L.K., R.K. Mann, P.S. Kayne, and M. Grunstein. 1991. Yeast histone $\mathrm{H} 4 \mathrm{~N}$-terminal sequence is required for promoter activation in vivo. Cell 65: 1023-1031.

Eberharter, A., T. Lechner, M. Goralik-Schramel, and P. Loidl. 1996. Purification and characterization of the cytoplasmic histone acetyltransferase B of maize embryos. FEBS Lett. 386: $75-81$.

Edmondson, D.G., M.M. Smith, and S.Y. Roth. 1996. Repression domain of the yeast global repressor tupl directly interacts with the histones H3 and H4. Genes \& Dev. 10: 12471259.

Eisenmann, D.M., C. Dollard, and F. Winston. 1989. SPT15, the gene encoding the yeast TATA binding factor TFIID, is required for normal trasncription in vivo. Cell 58: 1183-1191.

Eisenmann, D.M., K.M. Arnt, S.L. Ricupero, J.W. Rooney, and F. Winston. 1992. SPT3 interacts with TFIID to allow normal transcription in Saccharomyces cerevisiae. Genes \& Dev. 6: 1319-1331.

Eisenmann, D.M., C. Chapon, S.M. Roberts, C. Dollard, and F. Winston. 1994. The Saccharomyces cerevisiae SPT8 gene encodes a very acidic protein that is functionally related to SPT3 and TATA-binding protein. Genetics 137: 647-657.

Fisher-Adams, G. and M. Grunstein. 1995. Yeast histone H4 and H3 N-termini have different effects on the chromatin structure of the GAL1 promoter. EMBO I. 14: 1468-1477.

Gansheroff, L.J., C. Dollard, P. Tan, and F. Winston. 1995. The Saccharomyces cerevisiae SPT7 gene encodes a very acidic protein important for transcription in vivo. Genetics 139: 523-536.

Georgakopoulos, T. and G. Thireas. 1992. Two distinct yeast transcriptional activators require the function of the GCN5 protein to promote normal levels of transcription. EMBO $I$. 11: 4145-4152.

Grunstein, M. 1990. Nucleosomes: Regulators of transcription. Trends Genet. 6: 395-400.

Hager, G., C. Smith, J. Svaren, and W. Horz. 1995. Initiation of expression: Remodelling genes. In Chromatin structure and gene expression (ed. S.C.R. Elgin), Vol. 9, pp. 89-103. IRL press, Oxford, UK.

Hecht, A., T. Laroche, S. Strahl-Bolsinger, S.M. Gasser, and M. Grunstein. 1995. Histone H3 and H4 N-termini interact with SIR3 and SIR4 proteins: A molecular model for the formation of heterochromatin in yeast. Cell 80: 583-592.

Hirschhorn, J.N. and F. Winston. 1988. SPT3 is required for normal levels of a-factor and alpha-factor expression in Saccharomyces cerevisiae. Mol. Cell. Biol. 8: 822-827.

Hirschhorn, J.N., S.A. Brown, C.D. Clark, and F. Winston. 1992. Evidence that SNF2/SWI2 and SNF5 activate transcription in yeast by altering chromatin structure. Genes \& Dev. 6: 2288-2298.

Horiuchi, I., N. Silverman, G.A. Marcus, and L. Guarente. 1995. $\mathrm{ADA} 3$, a putative transcriptional adaptor, consist of two seperatable domains and interacts with ADA2 and GCN5 in a trimeric complex. Mol. Cell. Biol. 15: 1203-1209.

Imbalzano, A.N., H. Kwon, M.R. Green, and R.E. Kingston. 1994. Facilitated binding of TATA-binding protein to nucleosomal DNA. Nature 370: 481-485.

Imbalzano, A.N., G.R. Schnitzler, and R.E. Kingston. 1996. Nucleosome disruption by human SWI/SNF complex is the absence of continued ATP hydrolysis. J. Biol. Chem. 271: 20726-20733.

Juan, L.-J., R.T. Utley, C.C. Adams, M. Vettese-Dadey, and J.L. Workman. 1994. Differential repression of transcription factor binding by histone $\mathrm{Hl}$ is regulated by the core histone amino termini. EMBO T. 13: 6031-6040.

Kleff, S., E.D. Andrulis, C.W. Anderson, and R. Sternglanz. 1995. Identification of a gene encoding a yeast histone H4 acetyltransferase. J. Biol. Chem. 270: 24674-24677.

Koleske, A.J. and R.A. Young. 1994. An RNA polymerase II holoenzyme responsive to activators. Nature 368: 466-469.

Kuo, M.-H., J. Brownell, R.E. Sobel, T.A. Ranalli, D.G. Edmonson, S.Y. Roth, and C.D. Allis. 1996. Transcription-linked acetylation by Gen $5 p$ of histones $\mathrm{H} 3$ and $\mathrm{H} 4$ at specific lysines. Nature 383: 269-272.

Kwon, H., A.N. Imbalzano, P.A. Khavarl, R.E. Kingston, and M.R. Green. 1994. Nucleosome disruption and enhancement of activator binding by a human SWI/SNF complex. Nature 370: 477-481.

Lee, D.Y., J.J. Hayes, D. Pruss, and A.P. Wolffe. 1993. A positive role for histone acetylation in transcription factor access to nucleosomal DNA. Cell 72: 73-84.

Li, Y., S. Bjorklund, Y.W. Jiang, Y.-J. Kim, W.S. Lane, D.J. Stillman, and R.D. Kornberg. 1995. Yeast global transcriptional regulators Sin 4 and Rgr1 are components of mediator complex/RNA polymerase II holoenzyme. Proc. Natl. Acad. Sci. 92: 10864-10868.

Loidl, P. 1994. Histone acetylation: Facts and questions. Chromosoma 103: 441-449.

López-Rodas, G., V. Tordera, M. Sanchez del Pino, and L. Franco. 1991. Subcellular localization and nucleosome specificity of yeast histone acetyltransferases. Biochemistry 30: 3728-3732.

Madison, J.M. and F. Winston. 1997. Evidence that Spt3 func- 
tionally interacts with Mot1, TFIIA, and TBP to confer promoter-specific transcriptional control in Saccharomyces cerevisiae. Mol. Cell. Biol. 17: 287-295.

Mann, R.K. and M. Grunstein. 1992. Histone H3 N-terminal mutations allow hyperactivation of the yeast GALl gene in vivo. $E M B O$ ). 11: 3297-3306.

Marcus, G., N. Silverman, S. Berger, J. Horiuchi, and L. Guarente. 1994. Functional similarities and physical association between GCN5 and ADA2-putative transcriptional adaptors. EMBO I. 13: 4807-4815.

Marcus, G.A., J. Horiuchi, N. Silverman, and L. Guarente. 1996. ADA5/SPT20 links the ADA and SPT genes, which are involved in trascription. Mol. Cell Biol. 16: 3197-3205.

Melcher, K. and S.A. Johnston. 1995. GAL4 interacts with TATA-binding protein and coactivators. Mol. Cell. Biol. 15: 2839-2848.

Mizzen, C.A., X.-J. Yang, J.E. Brownell, A.J. Bannister, T. OwenHughes, J. Workman, L. Wang, S.L. Berger, T. Kouzarides, Y. Nakatani, and C.D. Allis. 1996. The TAF 250 subunit of TFIID has histone acetyltransferase activity. Cell 87: $1261-$ 1270.

Norton, V.G., B.S. Imai, P. Yau, and E.M. Bradbury. 1989. Histone acetylation reduces nucleosome core particle linking number change. Cell 57: 449-457.

Norton, V.G., K.W. Marvin, P. Yau, and E.M. Bradbury. 1990. Nucleosome linking number change controlled by acetylation of histones $\mathrm{H} 3$ and H4. I. Biol. Chem. 265: 1984819852.

Ogryzko, V.V., R.L. Schiltz, V. Russanova, B.H. Howard, and Y. Nakatani. 1996. The transcriptional coactivators p300 and CBP are histone acetyltransferases. Cell 87: 953-959.

Owen-Hughes, T.A. and J.L. Workman. 1994. Experimental analysis of chromatin function in transcription control. Crit. Rev. Eukaryotic Gene Expression 4: 403-441.

Owen-Hughes, T., R.T. Utley, J. Cote, C.L. Peterson, and J.L. Workman. 1996. Persistent site-specific remodeling of a nucleosome array by transient action of the SWI/SNF complex. Science 273: 513-516.

Parthun, M.R., J. Widom, and D.E. Gottschling. 1996. The major cytoplasmic histone acetyltransferase in yeast: Links to chromatin replication and histone metabolism. Cell 87: 8594.

Peterson, C.L., A. Dingwall, and M.P. Scott. 1994. Five SWI/ $S N F$ gene products are components of a large multisubunit complex required for transcriptional enhancement. Proc. Natl. Acad. Sci. 91: 2905-2908.

Piña, B., S. Berger, A. Marcus, N. Silverman, J. Agapite, and L. Guarente. 1993. ADA3: A gene, identified by resistance to GAL4-VP16, with properties similar to and different from those of ADA2. Mol. Cell. Biol. 13: 5981-5989.

Roberts, S.M. and F. Winston. 1996. SPT20/ADA5 encodes a novel protein functionally related to the TATA-binding protein and important for transcription in Saccharomyces cerevisiae. Mol. Cell. Biol. 16: 3206-3213.

-1997. Essential functional interactions of SAGA, a Saccaromyces cerevisiae complex of Spt, Ada and GCN5 proteins, with the Snf/Swi and Srt/mediator complexes. Genetics (in press).

Roth, S.Y. and C.D. Allis. 1996. Histone acetylation and chromatin assembly: A single escort, multiple dances? Cell 87: 5-8.

Saleh, A., V. Lang, R. Cook, and C.L. Brandl. 1997. Identification of native complexes containing the yeast coactivator/repressor proteins NGG1/ADA3 and ADA2. J. Biol. Chem. 9: 5571-5578.

Silvermann, N., J. Agapite, and L. Guarente. 1994. Yeast ADA2 protein binds to the VP16 protein activation domain and activates transcription. Proc. Natl. Acad. Sci. 91: 11665-11668.

Steger, D.J. and J.L. Workman. 1996. Remodeling chromatin structures for transcription: What happens to the histones? BioEssays 18: 875-884.

Svaren, J. and W. Horz. 1996. Regulation of gene expression by nucleosomes. Curr. Opin. Genet. Dev. 6: 164-170.

Thompson, J.S., X. Ling, and M. Grunstein. 1994. Histone H3 amino terminus is required for telomeric and silent mating locus repression in yeast. Nature 369: 245-247.

Tsukiyama, T. and C. Wu. 1995. Purification and properties of an ATP dependent nucleosome remodeling factor. Cell 83: 1011-1020.

Turner, B.M. and L.P. O'Neill. 1995. Histone acetylation in chromatin and chromosomes. Semin. Cell Biol. 6: 229-236.

Vettese-Dadey, M., P. Walter, H. Chen, L.-J. Juan, and J.L. Workman. 1994. Role of the histone amino termini in facilitated binding of a transcription factor, GAL4-AH, to nucleosome cores. Mol. Cell. Biol. 14: 970-981.

Vettese-Dadey, M., P.A. Grant, T.R. Hebbes, C. Crane-Robinson, C.D. Allis, and J.L. Workman. 1996. Acetylation of histone $\mathrm{H} 4$ plays a primary role in enhancing transcription factor binding to nucleosomal DNA in vitro. EMBO J. 15: 25082518.

Wang, L., C. Mizzen, C. Ying, R. Candau, N. Barlev, J. Brownell, C.D. Allis, and S.L. Berger. 1997. Histone acetyltransferase activity is conserved between yeast and human GCN5 and is required for complementation of growth and transcriptional activation. Mol. Cell. Biol. 17: 519-527.

Wang, W., J. Cote, Y. Xue, S. Zhou, P.A. Khavari, S.R. Biggar, C. Muchardt, G.V. Kalpana, S.P. Goff, M. Yaniv, J.L. Workman, and G.R. Crabtree. 1996. Purification and biochemical heterogeneity of the mammalian SWI/SNF complex. EMBO $\%$. 15: $5370-5382$.

Winston, F. and M. Carlson. 1992. Yeast SNF/SWI transcriptional activators and the SPT/SIN chromatin connection. Trends Genet. 8: 387-391.

Winston, F., K.J. Durbin, and G.R. Fink. 1984. The SPT3 gene is required for normal transcription of Ty elements in $S$. cerevisiae. Cell 39: 649-656.

Winston, F., C. Dollard, E.A. Malone, J. Clare, J.G. Kapakos, P. Farabaugh, and P.L. Minehart. 1987. Three genes are required for transactivation of Ty transcription in yeast. Genetics 115: 649-656.

Workman, J.L., I.C.A. Taylor, R.E. Kingston, and R.G. Roeder. 1991. Control of class II gene transcription during in vitro nucleosome assembly. Methods Cell. Biol. 35: 419-447.

Yang, X.-J., V.V. Ogryzko, J. Nishikawa, B. Howard, and Y. Nakatani. 1996. A p300/CBP-associated factor that competes with the adenoviral oncoprotein E1A. Nature 382: 319-324. 


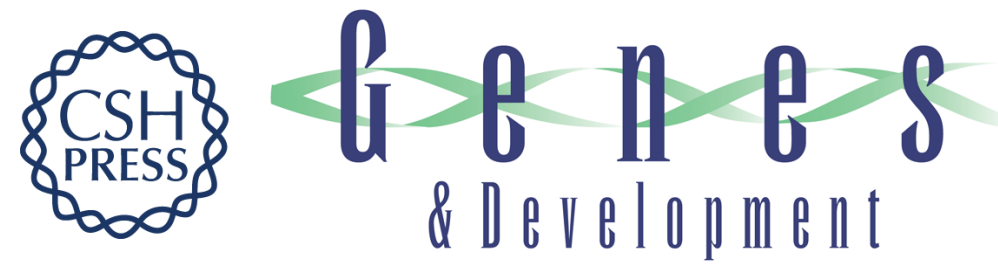

\section{Yeast Gcn5 functions in two multisubunit complexes to acetylate nucleosomal histones: characterization of an Ada complex and the SAGA (Spt/Ada) complex.}

P A Grant, L Duggan, J Côté, et al.

Genes Dev. 1997, 11:

Access the most recent version at doi:10.1101/gad.11.13.1640

References This article cites 71 articles, 29 of which can be accessed free at:

http://genesdev.cshlp.org/content/11/13/1640.full.html\#ref-list-1

License

Email Alerting Service

Receive free email alerts when new articles cite this article - sign up in the box at the top right corner of the article or click here.

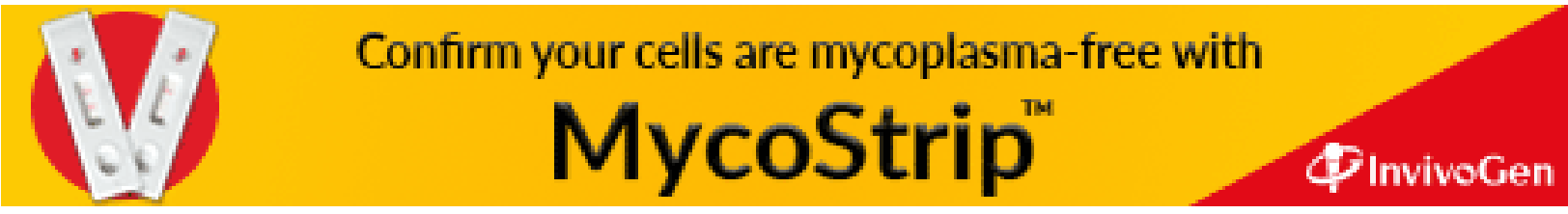

